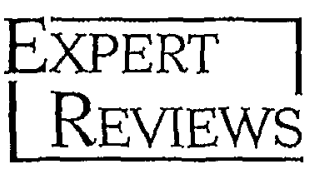

\title{
Development of rapid, automated diagnostics for infectious disease: advances and challenges
}

\author{
Expert Rev. Med. Devices 6(6), 641-651 (2009)
}

The last 2 years has seen an exponential rise in the amount of research funding made available for the development of rapid diagnostic devices for infectious agents of medical importance. This review reports on several such projects. These highlight the development of fully automated devices for rapid diagnostics, ranging from fully automated real-time PCR-based detection methods to fully automated PCR- and array-based machines for the detection and typing of influenza. This review will also highlight the importance of refocusing work on classical immunoassay techniques, showing how biosensor-based immunoassays can greatly enhance existing assays and at a much reduced cost to molecular-based methods.

KeYwords: automated $•$ infectious disease $\cdot$ molecular diagnostics $•$ PCR - point of care

Importance of rapid diagnosis of infectious disease

Infectious disease represents the greatest risk to global human health. This can range from classical infectious diseases, such as TB, cholera, dysentery and typhoid, annual epidemics, such as norovirus, influenza and seasonal colds, emerging infectious diseases, such as avian influenza and hemorrhagic fevers, through to global pandemics, such as HIV and the current newly emerged HINIv outbreak (commonly referred to as swine $\mathrm{flu}$ ). In the UK alone, infectious diseases account for $10 \%$ of all deaths recorded annually and are responsible for a third of all general practitioner consultations. The projected total cost for treatment of infectious diseases in the UK is approximately $£ 6$ billion per annum.

In addition, public perception and awareness of infectious diseases has increased in recent years owing to increased coverage in the media of high-profile outbreaks of infectious diseases. Particular attention has been paid to cases of the human H5N1 highly pathogenic avian influenza infection and to the introduction of the virus into UK wild bird and poultry flocks. Public perception has also increased dramatically with regards to healthcare-associated infections, in particular methicillin-resistant Staphylococcus aureus (MRSA) and Clostridium diffecile infections, and fatal outbreaks in hospitals. According to official figures on the Health Protection Agency website [101], there were 3210 cases of MRSA bacteremia reported in the UK in 2008 with 1652 deaths, and an astonishing 81,412 reported cases of $C$. diffficile infection, with 8324 deaths (fatality figures are from Office for National Statistics data, where the organism was named on death cercificates [101]).

Despite the obvious burden to human health and economic wealth presented by infectious diseases, the approach taken to diagnosis and effective treatment of these is firmly entrenched in classical microbiology of the early- and mid20th Century. Diagnosis for almost all infectious diseases caused by bacteria is still based on classical microscopic- and culture-based methodology. By adopting a culture-based program of infectious disease diagnosis, laboratories can perform tests on hundreds, if not, thousands of samples per day using very cheap culture media and techniques able to be employed by semiskilled workers. It also provides clinical microbiologists with isolated bacterial cultures, which can be further characterized if necessary, such as antibiotic-resistance profiles or epidemiological testing in the event of an outbreak situation. 


\section{Classical diagnostics for infectious diseases}

To alleviate the burden of infectious diseases, diagnostic tests have been developed to identify pathogenic agents. This speeds up the appropriate treatment of patients and allows specific targeted drugs to be used, slowing the spread of infection to others [1]. The types of methods used include microscopy, culture, antigen detection and immunoserology [2]. The technique commonly used in clinical settings is culture on selective and chromogenic agars. In the last decade, many chromogenic agars have been developed to aid the rapid identification of bacterial pathogens in several disease states, for example urinary tract infections (UTIs) and bacteremia [3-5]. Agars have been developed for specific pathogens, such as acrylonitrile-butadiene-styrene medium for Salmonella [6], candida diagnostic agar for Candida [7] and $S$. aureus ID agar or CHROMagar MRSA for MRSA [8-10]. Media used for potentially mixed pathogenic samples, such as those from UTI cases, include UriSelect3, Rainbow ${ }^{\circledR}$ Agar UTI medium and chromogenic UTI medium [3].

Microscopy and culture are also complemenred in most clinical diagnostic laboratories, with techniques such as antigen detection and serology (Figure 1). These methods could be considered the forerunners of rapid diagnostics, as they principally remove the need for time-consuming, culture-based methods to direct detection of the infectious agent, or a response against that infectious agent. Both methods are antibody-based and are principally run on the basis of ELISA or immunofluorescent antigen testing. While both techniques speed up detection and diagnosis, there are numerous inherent problems with these techniques, as highlighted in Box 1 . Despite this, commercial antigen detection and serology assays represent a huge matket and are commonly used for the diagnosis of HIV, influenza, chlamydia and numerous other virus infections. Their use for diagnosis of viral infections has been particularly well employed by clinical laboratories, with the ELVIS technology a notable success for herpes simplex virus detection, which uses genetically modified cells that express the bacterial enzyme $\beta$-galactosidase in the presence of the virus, which is easily detected histochemically [i1]. The use of rapid diagnostics is perfect for such cases as culture and isolation of viruses, but it is extremely time consuming and cumbersome, relying on cultured eukaryotic cells or embryonated eggs, with culture often taking as long as 7-14 days. Similarly, obligate intracellular organisms, such as Chlamydio, are much simpler to diagnose using antigen-detection tests, as opposed to intracellular culture of samples. In addition, many of these tests are now fully automated in clinical laboratories through the use of systems such as the Axsym ${ }^{\otimes}$ machine (Abbot Diagnostics).

As the employment of serological and antigen-detection tests has increased for infectious organisms that are difficult to culture, the need for rapidity in diagnosing bacterial infections has also gathered pace. Many clinical laboratories now use automated systems such as the BACTECTM system for bacterial blood cultures and Mycobacterium detection (Becton Dickinson). This works using barcode-labeled culture tubes that are inoculated and incubated. The incubator contains a light-emitting diode, and a scanner detects color changes in the inoculation vials as a result of $\mathrm{CO}_{2}$ production by bacterial respiration, producing an audible alarm to alert the microbiologist to the presence of bacteria in what should be a sterile sample.

\section{Drawbacks}

All diagnostic techniques have their shortcomings. A summary of the main challenges faced by traditional infectious disease diagnostic methods is presented in Box 1 . Culture-based diagnostic methods suffer particularly from the time taken to obtain a definitive result. Culture requires time to allow the bacteria of interest to grow, which is generally $24-72 \mathrm{~h}$. Only after this time can the result be seen and this represents a huge delay to the treatment of patients. Ledeboer et al. investigated making the detection of Enterococcus spp. as rapid as possible using agar, but the fastest they were able to make their culture-based assay was $24 \mathrm{hl}$ [4]. If an organism has fastidious growing requirements, or is just slow growing, the diagnostic time is lengthened further. Culture methods also only account for those organisms that can be grown in the laboratory - those that cannot go unrecognized by these techniques.

Apart from being time consuming, culture techniques are laboratory bound owing to the amount of equipment and reagents required to run them. This means that samples must be shipped to a laboratory before they can be analyzed. If collected in a hospital, this is not such a problem, as samples can be analyzed in-house in hospital laboratories. However, this is not the case with samples collected outside of hospitals. During transport, samples may deteriorate or change from the state in which they were first collected owing to changes in temperature and aerobic status - such changes can have profound effects on the bacterial populations in the samples; thus, if a microbiological test is intended, it is important to store the samples carefully during transport. Disregarding changes in the sample itself, transport time lengthens the diagnostic procedure. Culture also requires a considerable amount of manual labor time preparing media, inoculating and attending to incubating cultures.

\section{Impact of molecular biology on diagnostics}

More advanced methods are now being used to supplement classical diagnostics utilizing nucleic acid probes specific for pathogens of interest, most notably in the diagnosis of blood culture samples using peptide nucleic acid FISH. This utilizes a fluorescent peptide nucleic acid that hybridizes to ribosomal RNA of septicemia pathogens and gives a positive identification for sepsis diagnosis [12]. The technique targets the $16 \mathrm{~s}$ RNA region of bacterial chromosomes, which are unique to each species and act as a fingerprint for bacteria. By designing a fluorescent probe that is complementary to this sequence, it is possible to detect bacteria at the molecular level by simply lysing cells in a sample in situ and adding the probe, then visualizing for fluorescence. This is very quick but also has drawbacks with regards to specificiry, for example distinguishing MRSA from methicillin-sensitive $S$, atrews (MSSA). 

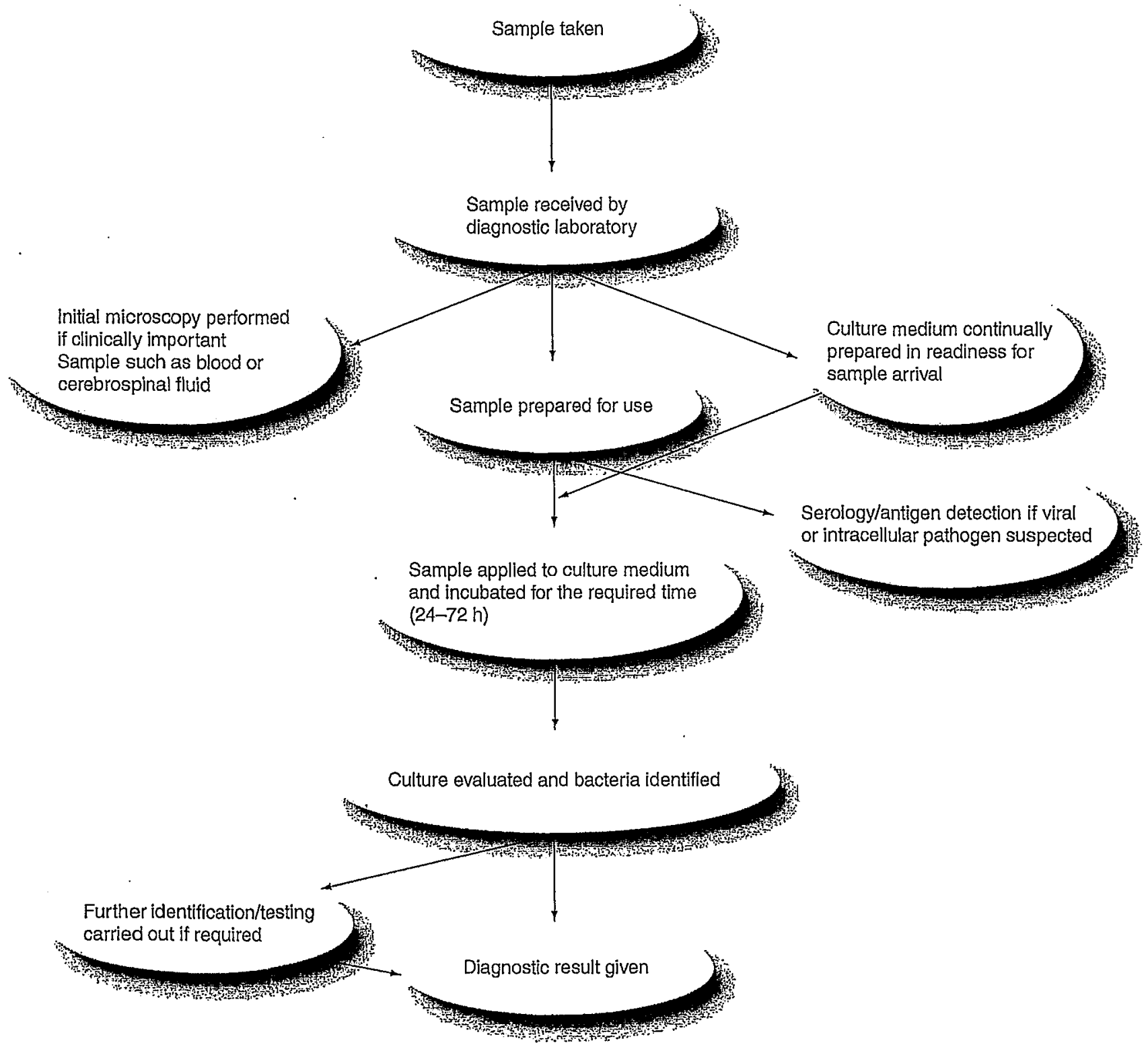

Figure 1. Processes involved in classical diagnosis of infectious disease, from receipt of sample through to confirmation of result.

The ability to amplify nucleic acids has opened the door to identifying pathogens by detecting the presence of their DNA in samples without the need to culture first to increase their numbers $[2,13]$. DNA detection can be achieved much more rapidly than culturing, thus diagnoses may be available in just a few hours. It avoids the problem posed by fastidious or nonculturable organisms and can be used to identify organisms more specifically than culture, since primers and probes may be designed for specific organisms (FIGURE 2). Amplification-based nucleic acid methods may be identified into three groups: target nucleic acid amplification, probe amplification or signal amplification [14].
Polymerase chain reaction, strand-displacement amplification and isothermal RNA self-sustaining sequence replication are examples of target amplification. The latter is the basis for nucleic acid sequence-based amplification and transcriptionmediated amplification. PCR consists of a number of temperature cycles that include a denaturing, annealing and sometimes an extension temperature [15]. The DNA template of choice (from a parhogenic bacterium for diagnostic purposes) is subjected to this cycle of temperature changes in the presence of a polymerase enzyme, free nucleotides, primer nucleotide sequences and chemical buffers. This enables the polymerase 


\section{Box 1. Limitations of traditional}

\section{diagnostic techniques.}

\section{Microscopy}

- Poor sensitivity

- Invasive

- False-positives obtained

Culture

- Time consuming

- Slow-growing organisms

- Uncultured/fastidious organisms

- Biohazard

Antigen detection

- False-positives occur

- Long-term antigen shedding

- Narrow detection window

Serology

- Negative in immune-compromised patients

- Complex interpretation

- Poor correlation with disease

- High background titers

- Crossreactivity

to create additional complimentary strands of DNA once the original strands have denatured and primer fragments have annealed. The product of the PCR, the DNA fragment selected by the primer placement, doubles during every cycle, thus increasing the amount of the chosen nucleic acid dramatically. The transcription-mediated amplification and nucleic acid sequence-based amplification reactions amplify RNA by the action of three enzymes: reverse transcriptase, RNase and RNA polymerase. First, $c D N A$ is synthesized by special primers, one end of which is target specific and the other end is promoter RNA polymerase. Reverse transcriptase synthesizes RNADNA hybrid, and the RNase digests the RNA component of this. The reverse transcriptase then synthesizes dsDNA, and finally, the RNA polymerase makes numerous RNA copies.

The ligase chain reaction (LCR) in the gapped LCR format is a combination of target- and probe-amplification processes, and the $Q B$ replicase amplification is an example of probe amplification [15]. In LCR, dsDNA is denatured by heating, and primers anneal to the single strands. Then, the DNA ligase joins the primers, and the product is again released by heating. This product goes on to become the template for further ligations. Gapped LCR simply adds a DNA polymerase step to fill a gap of a few bases left between the primers, before the ligase may join them. In $Q B$ replicase amplification, the $R N A$ probe anneals to the target and the hybrids are captured; the probe is then removed and amplified by the QB replicase. However, problems have been seen regarding the separation of hybridized and nonhybridized probe.

All of the aforementioned amplification reactions have been improved by the advent of real-time PCR rechnology. This has the benefit over conventional amplification reactions in that it does not require electrophoresis of products after the amplification reaction, minimizing postmethod contamination, but rather uses fluorescently labeled nucleotides (Sybr technology) or a fluorescently labeled probe complementary to the targer sequence, which anneals between the two primers used in the amplification reaction (TaqMan technology; Roche). TaqMan works by addition of a Aluorophore and a quencher molecule to the probe. In the absence of complementary target molecules, the quencher inhibits the emission of light by the fluorophore. If bound to target DNA, the molecules are separated by distance, and fluorescence is emitted. This is detected by a sensor that scans the reaction after each PCR cycle, hence the real-rime detection of target molecules. Real-time PCR is a much faster process, and target molecules can be detected in as little as $30 \mathrm{~min}$ if abundant in a test sample [16]. The two main benefits of this real-time scanning process are that a positive sample can be detected during the PCR assay, rather than having to wait for the cycling and then a further electrophoresis step, and that as PCR and incorporation of fluorescence is a logarithmic process, one can actually quantify the amount of target in a sample by using a calibration curve composed via positive-control samples containing known amounts of the target. This creates the power of quantifiable culture-based diagnosis using the rapidity of molecular-based tests.

In addition, microrray technology could also be of use in diagnostics for infectious agents [17]. This involves glass slides that contain ssDNA molecules complementary to pathogenspecific sequences. By amplifying the microbial DNA or RNA present in a sample, it is potentially possible to identify all microbes present in a clinical sample on one test assay. The amplification incorporates fluorescently labeled nucleotides into the amplified product, and hybridization is assessed using laser excitation and fuorescence emission readings.

There are an astonishing number of peer-reviewed publications on the development and implementation of PCR-based detection assays for infectious agents, far too many to cover in a concise review; however, a fine example of the process behind the rationale and design of such assays is the development of a PCR assay for MRSA specifically, rather than all S. aureus strains. Methicillin resistance is conferred by a penicillin-binding protein called penicillin-binding protein 2a (PBP2a), which is coded for by the mecA gene [18]. A PCR assay was designed to derect the presence of this gene [12]; however, this assay also amplified other Staphylococcus species that were coagulase-negative in samples [20], creating a false positive for MRSA, and thus different assays were designed to be more specific. Reischl et al. used a duplex assay that combined primers for the mec $A$ gene and primers for a $S$. aureusspecific marker gene, such as nuc or sa442 [20]. However, this approach also led to false MRSA positives by picking up MSSA and coagulase-negative methicillin-resistant Staphylococci present in the same sample. A more refined, tandem-target approach was also used by Warren et al., whose assay targeted a sequence from the mobile genetic element that holds the mec $A$ gene, $S C C m e c$, and a sequence from the of $X$ region, a conserved open reading frame in which the SCCmec can be integrated into the genome and is uniquely found in MRSA [21]. Francois et al. used 
a triplex assay to identify between $S$. aureus and Staphylococcus epidermidis [22]. Their assay included primers for $m e c A$ and fem $A$ specific for $S$. aureus and fam $A$ specific for $S$ epidermidis.

\section{Potential problems in developing} molecular detection methods Molecular procedures have the risk of showing false-positive or -negative results [13]. False-positive results are primarily due to contamination of the reaction mixture from other samples and products of previous amplifications. Contamination during pipetting due to aerosols is also possible, since nucleic acid amplification is very sensitive and will pick up on tiny amounts of a contaminant. To combat the problem of contamination, urasil- $N$-glycosylase can be added to the reaction mix [23]; however, this does not remove the necessity for good laboratory practice when preparing molecular assays. The use of automated nucleic acid extraction and amplification techniques may also reduce contamination.

False-negative results could be caused by a poorly designed assay that does nor detect the target sensitively enough or only detects it when the target is present in high quantities. In such cases, the assay should be redesigned or a more effective target should be chosen for that pathogen. By their nature, molecular assays only use small amounts of a sample, considerably smaller than in culture techniques. Therefore, if the pathogen for detection is present in low numbers in the first place, it is more likely to be missed when only a very small amounts of the subsample of the original sample is used. In this case, replicate assays may help to alleviate the problem, although they will add time and cost to the overall diagnostic process, so it would not be favored in a clinical setting. Another cause of false negatives in clinical samples is the presence of inhibitors of nucleic acid amplification in the samples. Clinical samples are likely to consist of blood or feces, both of which contain substances that inhibit DNA-amplification reactions $[24,25]$. TABzE 1 gives a list of inhibitory substances in clinical samples with their method of inhibition, if known. The compounds are inhibitory because they interact with one or more of the reagents within the reaction mixtures. Anticoagulants, added to the samples to make them more suitable for some analyses, chelate $\mathrm{Mg}^{2+}$ ions added to the reaction in the form of $\mathrm{MgCl}_{2}$, which reduces polymerase effectiveness [26]. Sodium polyanecholesulfothate is added to blood cultures for its anticoagulant properties, and it is particularly difficult to remove when extracting DNA. since it is a very similar molecule to DNA, sharing many of the same properties [27]. Morata $e t a l$. also found that incorporating
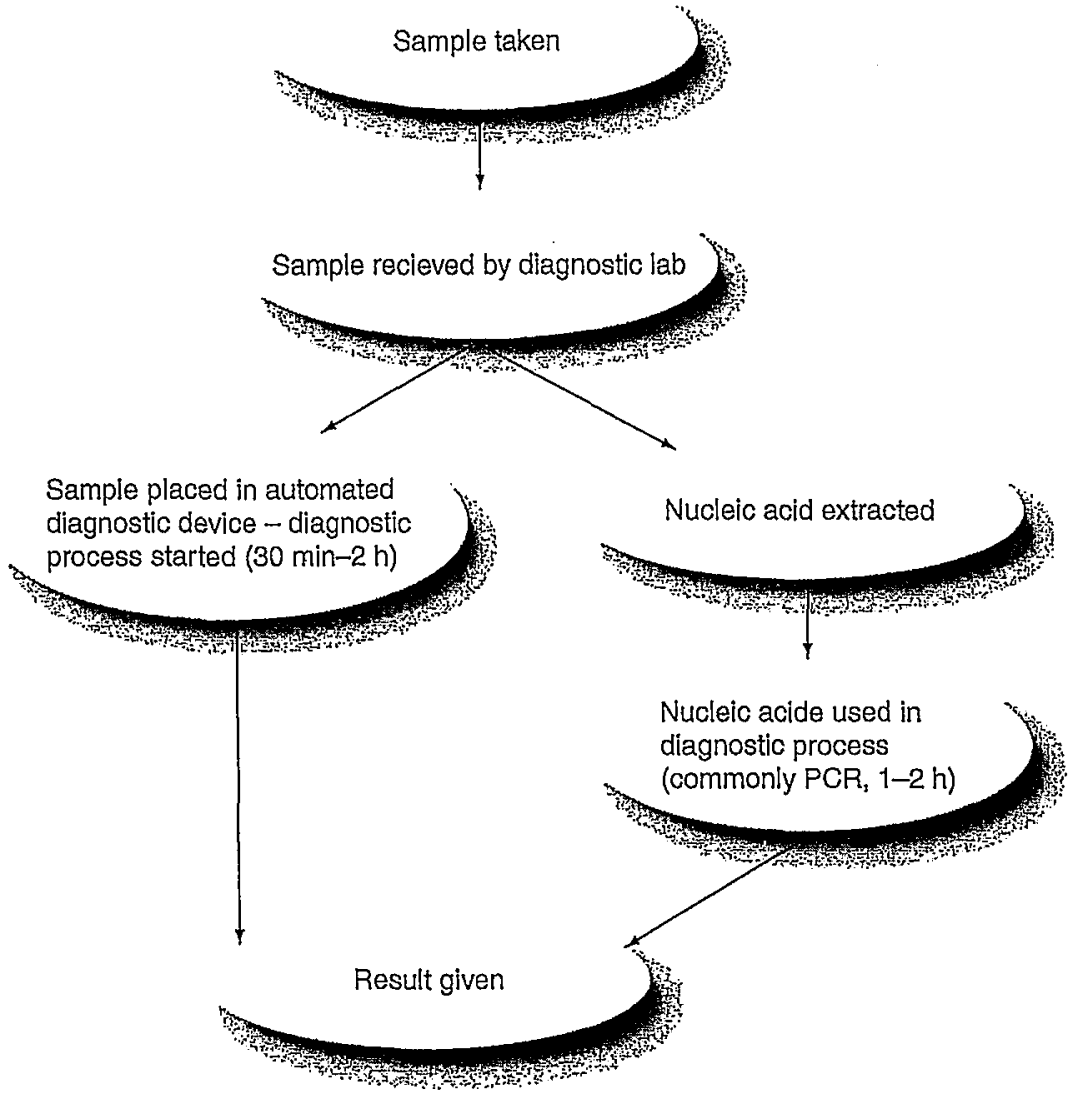

Figure 2. Molecular diagnostic process can, in theory, greatly simplify and speed up the process of diagnosis of infectious disease.

more washing steps into their DNA extraction protocol removed inhibitors to allow successful PCR, although it also meant that the final yield of DNA was much lower [28]. Compounds within the blood itself also act as inhibitors, including hemoglobin, lactoferrin, heme and $\operatorname{IgG}[29,30]$. The DNA extracted from fecal samples also shows amplification inhibition if not purified prior to use. There are numerous commercial kits available to extract DNA from feces; some that have been specifically designed for stool samples include the QIAamp ${ }^{\otimes}$ DNA stool minikit (Qiagen,

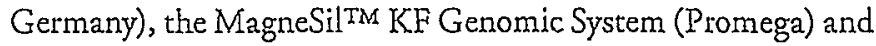
the MagaZorb ${ }^{\circledR}$ DNA Mini Prep kit (Promega). Although these kits yield DNA that gives positive results for amplification, they do not perform as effectively with fecal samples when compared with extractions from samples of pure bacterial culture [31-33].

One other key challenge for molecular-based diagnostics is the standardization of assays between laboratories. There are an extremely limired number of commercially standardized molecular assays available, compared with the enormous number of 'inhouse' real-time PCR assays reported in the scientific literature each month. This creates problems in that diagnostic laboratories may be using different assays with differing degrees of sensitivity and specificity. Indeed, it has been shown that the use of different in-house real-time PCR tests can impair direct comparison of diagnostics between laboratories [34]. One key way of subverting 
Table 1. Compounds found in clinical samples that inhibit nucleic acid amplification and their modes of action.

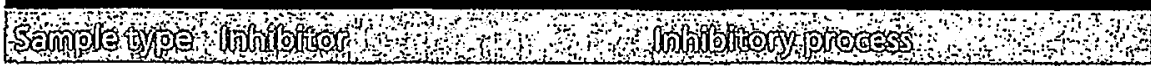

Blood

Hemoglobin

Releases iron ions

Lactoferrin

Releases iron ions

Interacts with nucleic acids

Heme

Chelates $\mathrm{Mg}^{2+}$

Leukocyte DNA

Anticoagulant: EDTA

Chelates $\mathrm{Mg}^{2+}$

Anticoagulant: heparin

Chelates $\mathrm{Mg}^{2+}$

Sodium polyanetholesulfonate

Immunoglobulin $G$

Interacts with target DNA

Bile salts

Chelates $\mathrm{Mg}^{2+}$

Bilirubin

Chelating agent

Urobilinogen

Chelating agent

Polysaccharides

Heavy metals

Urine

Urea

these problems is by engaging diagnostic laboratories employing molecular-based diagnostics in well-defined and robust qualitycontrol programs [34]. This is a technique that has worked well in standardizing the detection of influenza in avian samples among the EU and the World Organisation for Animal Health reference laboratories. Standardizing internal controls used in real-time PCR assays can also assist with the problem stated previously of PCR inhibitors in samples. Again, there are numerous 'homebrew' internal controls reported in the literature, but the design and use of good appropriate intemal controls within a PCR are essential if it is to be used with confidence in a diagnostic setting.

Perhaps the most fundamental challenge to implementing molecular diagnostics for clinical use is that of assay design, which is essentially which genes to target. This review has already described the challenges associated with designing a MRSAspecific assay, and, indeed, the short synopsis presented is very much an abbreviation of the problem. As our knowledge of bacteria and their genomes escalates, it becomes clear that the concept of 'virulence' genes is outdated and that, owing to genetic exchange between microbes, there are many ubiquitous organisms that contain genes once thought to be unique to pathogens. Similaty, there are numerous bacterial pathogens that appear to carry no real virulence genes, which are indispensable for their ability to cause disease [35]. This leads to a major challenge in using genetic identification for diagnostics; put simply, relying on one gene to identify a pathogen within a sample from normal microbial flora is becoming less and less reliable for a large number of pathogenic bacteria. Again, this is perfectly illustrated by the case of MRSA, where detection of the mecA gene alone is not sufficient to type an organism as MRSA; even using two target genes can lead to confused diagnosis owing to multiple bacteria present in a sample containing one or more of the target genes.

A similar problem exists in C. difficile, where debate exists on which combination of toxin $A$ and $B$ is relevant to consider the organism a pathogen. A recent landmark publication has suggested that only toxin $B$ is essential for human virulence [36]. Similarly, epidemiology laboratories also need to distinguish between classical $C$. difficile and the emerging hypervirulent $C$. difficile responsible for the mass healthcare fatal outbreaks reported. The major difference betwreen these is a minor mutation in a gene that regulates production of toxin $B$, which is practically impossible to assess by conventional PCR [37].

\section{More advanced uses of molecular biological technology}

In order for molecular diagnostics to be utilized in a clinical setring with the required level of accuracy and reliability, it is clear that more sophisticated strategies are required than simply PCR. At the very least, welldesigned and robust multiplex PCR assays that target unique sets of genes are required to unequivocally identify a large number of pathogenic organisms. Alternatively, strategies, such as real-time PCR and melt-curve analysis, can be used to identify pathogens where simple genetic mutations render them pathogens compared with their less harmful close relatives [38]. This is an extremely powerful tool that allows the PCR assay to detect single base pair differences in the gene being targeted. It does so by allowing the PCR to progress to the end of the reaction, and then measures the exact temperature at which the amplified product denatures into ssDNA (the melt temperature). This exact temperature will vary if the sequence differs by as little as one nucleotide. Such modifications of real-time PCR would allow diagnostic assays to circumvent problems such as the one described previously for $C$. difficile, and may also have added benefits during diagnosis, such as detection of mutations in target genes, a key feature of note during, for example, influenza outbreaks.

In addition, the adaptation of microrray technology to diagnostics would allow full differentiation of a pathogen from a nonpathogen. This could, in theory, allow the nucleic acid from a sample to be extracted, then hybridized to a glass slide containing DNA fragments complementary to the genes of interest, unique to the pathogen being tested for. In theory, this could also allow sample type screens, racher than individual tests for 
each pathogen. For example, a microarray slide could be created containing a number of unique gene segments for all pathogens associated with respiratory disease. This would then allow the clinical laboratory to process a respiratory sample and then hybridize to the slide to allow identification of all pathogens present in that sample in one quick assay. Another added benefit is that such a gene-panning approach could also theoretically employ antibiotic resistance genes, so that almost all antibiotic resistances present in a sample could be ascertained, which is still a major hurdle in persuading clinicians to adopt molecular diagnostics over culture-based isolation and characterization of the resulting isolare. While this sounds like diagnostic nirvana, there are rnumerous obstacles to such technology being employed in a clinical setring. These include the cost and level of user skill required for the technology, and also the amount of pathogen DNA required to fluorescently label and then hybridize to the slide to produce a detectable signal. This can be overcome by PCR-based amplification of the DNA in the sample, but this is incredibly difficult if attempting to amplify hundreds of gene segments for the type of array previously mentioned [17].

\section{Towards an ideal rapid diagnostic device: fully automated devices}

In order for rapid diagnostics to be fully accepted in clinical and point-of-care settings, the major challenge is automation. This would save labor time and, ideally, allow multiple samples to be analyzed at once. It would reduce the time of exposure of technical staff to potentially infectious samples and may reduce contamination of samples, thus reducing false-positive results. Automation should permit greater standardization of tests, and systems that are easy to use would open the diagnostic process to operation by unskilled staff, increasing the number of people able to run diagnostic analyses. A portable, automated diagnostic system would be the ideal target for development, as this would dramarically increase diagnostic flexibility by allowing point-of-care diagnosis and diagnostic ability in nonclinical settings [39]. For an automated test to be incorporated into routine clinical use, it must be as effective as current manual methods, with the same level of accuracy, be time- and labor-saving and cost effective. Ideally, an automated system would incorporate sample preparation, most commonly in the form of nucleic acid extraction, with

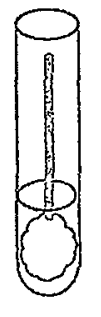

\section{Sample collection}

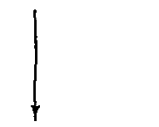

Bacterial cell lysis if required (vortex/heat/enzyme)
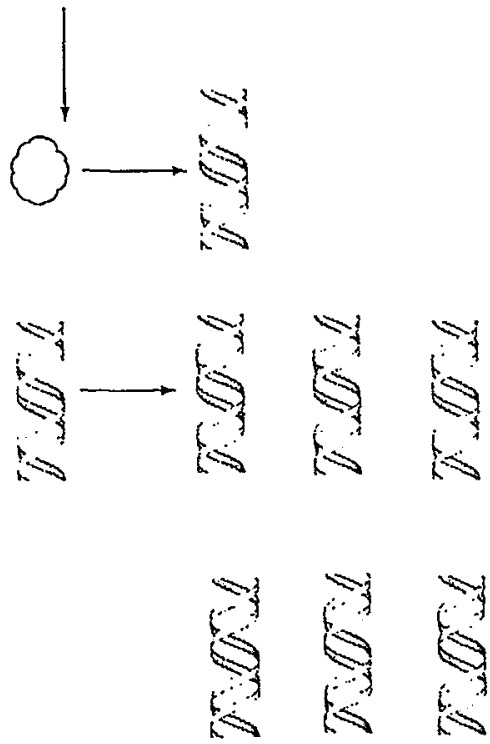

Result reported

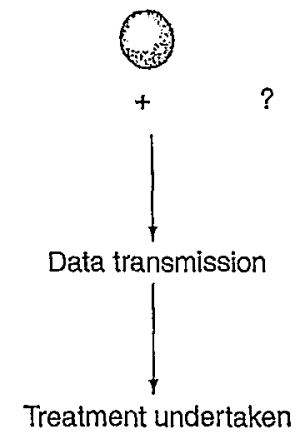

Expert Rev. Med. Devices (C) Future Science Group (2009)

Figure 3. Ultimate molecular diagnostic protocol. A fully automated device producing a specific, sensitive and reliable diagnosis in a 30-min time frame. + Positive for pathogen; -: Negative for pathogen; ?: Result unclear.

some form of real-time PCR or microarray-based detection of pathogen DNA involving fluorescent labeling and signal detection (Figurk 3).

Commercial developers have begun to address some of these requirements with regards to automated DNA extraction from samples, and two of the devices that have been most extensively tested are the MagNA Pure LC (Roche) and the BioRobot ${ }^{\circledR}$ M48 (Qiagen). When compared with established manual methods, these automated procedures were found to be comparable or better owing to reduced contamination [40-45]. Costa et al. were also able to incorporate an ultraviolet decontamination step into their assay in the MagNA Pure LC to further reduce contamination [46]. 
Table 2. Automated/semi-automated diagnostic systems.

\begin{tabular}{|c|c|c|c|}
\hline Gen-Probe Inc. & AccuProbe TM culture & Campylobacter & Probe hybridization \\
\hline \multirow[t]{2}{*}{ Neogen Corp. } & GENE-TRAK & Salmonella & Probe hybridization \\
\hline & GeneQuence $^{\mathscr{Q}}$ & Salmonella & $\begin{array}{l}\text { Probe hybridization causing a } \\
\text { colour change detected } \\
\text { spectrophotometrically } \\
\text { (automated, } 372 \text { samples in } \sim 4 \mathrm{~h} \text { ) }\end{array}$ \\
\hline Oxiod (ThermoFisher Scientific) & BAX Salmonella Kit & Salmonella & PCR \\
\hline
\end{tabular}

BAX System Q7 from Du Pont

Qualicon Inc.

Roche Diagnostics

$B A{ }^{\circledast}$ Campylobacter/jejuni/coli/lari Kit

LightCycler ${ }^{\circledR}$ Foodproof Detection Kit

RAPID ${ }^{\oplus}$ LT Food Security System (Salmonella LT)

Pathogen Test Kit

Artus Biotech

Real Alert PCR Kits

Liminex Corp.

Luminex LabMAPTM System

AnDiatec $\mathrm{GmbH}$

AnDiatec ${ }^{\circledR}$ Salmonella PCR-ELISA

RT: Real time.

Magnetic DNA extraction methods lend themselves to automation since they remove the need for liquid-handling steps; the DNA, once liberated from the cells in question, is bound to magnetic particles and transported between different washing and eluting solutions by an automated magnetic arm. These protocols often do not require centrifugation or heating steps, which makes automation more straightforward. The Enigma FL PCR-Light ${ }^{\circledR}$ (Enigma Diagnostics, Wiltshire, UK) incorporates a magneticbased DNA extraction process, including a centrifugation step, with real-time PCR in a portable diagnostic device designed for use by the army. This makes use of lyophilized PCR reagents that are stable for storage and provides a diagnostic result in less than $30 \mathrm{~min}$ [39]. Further modifications are currently being made to this technology to better tailor it to the clinical point-of-care market.

Another aspect of molecular diagnostic automation that requires attention is the addition of the initial sample preparation stages to the molecular assay. This, in most cases, will involve the lysis of bacterial cells and extraction of their DNA. The effect of amplification inhibitors that are copurified with DNA from clinical samples has been discussed earlier; however; this is not the only challenge for DNA extraction. The lysis of bacterial cells, particularly Gram-positive species, is a barrier since it requires processes that are potentially difficult to incorporate into an automated system. The principle methods used to lyse bacterial cells include heating, enzyme action and physical distuption, usually by beating with glass or porcelain beads. In many cases, manual protocols employ more than one method; the QIAamp ${ }^{\circledR}$ mini stool kit and GenElute ${ }^{\mathrm{TM}}$ kit use both heat and enzyme action, while the FastDNA ${ }^{\circledR}$ Soil kit uses physical disruption followed by enzyme action. Adding an enzyme reagent to the automated process is not as complicated as adding a heating element (may

\section{Campylobacter RT-PCR \\ Salmonella PCR}

Salmonella (also RT-PCR using freeze-dried Campylobacter in RAPID reagent pellets defence system)

Campy/Salmonella
Campy/Salmonella
Campy/Salmonella
Salmonella

PCR

PCR

PCR-ELISA need to heat up to $95^{\circ} \mathrm{C}$ for bacterial cells) or a vortex action sufficiently vigorous to break open cells. However, an enzyme alone is not always enough to fully lyse cells, which is why multiple lysis methods are used in many manual kits. The nature of clinical samples adds extra difficulty due to the presence of viscous or particular substances. Producing a portable device that will effectively extract DNA from clinical samples will be a major step forward in clinical diagnostics.

Perhaps the greatest challenge to producing a fully automated diagnostic device is the integration of all of the component stages into one small footprint machine. Integrating sample preparation with DNA extraction, followed by amplification/DNA labeling and then readout, are major engineering challenges that require a very much interdisciplinarian approach to solve.

\section{Expert commentary}

In line with the contrasting advances and challenges listed in this review, the development of point-of-care rapid diagnostics is an area that is a major focus of research sources, yet at the same time, very few devices are currently commercially available. Current automated devices in use or development are primarily targeted toward the food industry or the military; examples are listed in TABLE 2. Further development of these devices is required to better suit them to mass clinical use.

Probably the greatest success for rapid diagnostics to date is the Cepheid GeneXpert ${ }^{\circledR}$ system, based on the SmartCycler ${ }^{\circledR}$ used in many clinical and research laboratories for real-time PCR and the various molecular tests developed for the sexually transmitted parhogens Cblamydia trachomatis and Neisseria gonomboeae (CTNG). The GeneXpert is a fully automated closed system that automates sample preparation, DNA amplification and detection. 
There are currently three commercial GeneXpert systems available for Enteroviral meningitis, Group B Streptococcal infections and, most notably and successfully, for MRSA detection [47-49]. CTNG tests have been developed by a number of different companies (TABLE 3) and are now routinely used in clinical settings. Indeed, the development of chlamydial tests based on nucleic acid-amplification technology has been considered the most important advance for the detection of chlamydial infections since cell culture.

The success of implementation of molecular-based diagnostic tests for CTNG should pave the way for more molecular diagnostics becoming common place in clinical laboratories, particularly when they replace cumbersome and tiresome culture- or serology-based diagnostics. A fine example of this is the recent implementation of the molecular test developed by the UK Health Protection Agency for HIN1v, or swine flu. After being developed and validated by the reference research laboratories, the real-time PCR was rolled out to all frontline clinical diagnostic laboratories to expedite the fast turn around of swine flu diagnosis. This molecular test completely replaced all serology-and culture-based techniques. This is a practice that has been employed by veterinary avian influenza laboratories for the last few years [50]. Howrever, one key point to understand is that molecular diagnostics should never be viewed as a way to replace conventional diagnostics but as a way of supplementing them, and may be best considered as a value-added tool to incorporate into the diagnostic algorithm.

\section{Five-year view}

As the amount of research funding for rapid point-of-care diagnostics has increased exponentially over the last 24 months, it is fair to hope that so too will the number of devices reaching the clinical market, particularly with funding schemes such as the EU FP7 funding initiatives, technology strategy board health technologies initiative and the NIHR Ideastinnovation small business research initiative. These funding schemes have seen several million pounds invested in small and medium enterprises and academic partnership research in an attempt to bring expert knowledge of pathogens and pathogen genomics, with experrise of developing and constructing state-of-the-art engineering solutions to rapid diagnostic devices.

In the next 5 years, we should see a wider choice of robust pointof-care devices made available to the medical profession. Devices such as the Enigma FL are now being further developed to create a small footprint device to perform fully automated sample extraction and real time PCR that can be used to diagnose healthcareassociated infections, CTNG, intestinal infectious diseases and influenza. The Enigma device is possibly the most advanced in the UK with respect to fully integrating all components of infectious disease diagnosis into a fully automated device.
The last two EU FP7 calls for research funding have heavily targeted the development of diagnostics, and this also should bear fruit in the next few years. Among several projects funded to speed up the diagnosis and detection of influenza in this initiative are the Enigma device for influenza detection based on real-time PCR, and the PortFastFlu project, which has garnered a lot of press interest worldwide owing to its design, incorporating sample preparation and amplification using small microfluidic microchips, and real-time microarray to allow detection and virus typing in one small, briefcase-sized machine. The technology is based on the HybLive technology developed by the French company Genewave, a spin-off small-to-medium enterprise from Ecole Polytechnique in Paris, as well as microfluidic expertise developed by Gaiker and Ikerlan of Spain.

While much of this review has focused on molecular-based detection of infectious agents, it is important to also note that many companies are aiming to speed up more classical methods of diagnosis, allowing them to be performed cheaper and far faster than they conventionally do. One such example is the recently reported Universal Sensors project. This uses biosensor technology to make the classical serological/antigen-detection ELISA tests faster, cheaper and much more sensitive, potentially as sensitive as PCR. The benefits are that the reagents and tests are greatly reduced in cost compared with molecular methods, and the actual test platform is highly portable, potentially a handheld device.

In brief, as more companies and academic researchers switch attention to the need for point-of-care rapid diagnostics, the next 5 years should see a real shift in the way infectious diseases are diagnosed and managed. The emphasis on general practitioner sampling and large throughput of samples by the clinical laboratory will begin to be heavily supplemented by the use of such machines. This will allow diagnosis of infectious diseases to occur faster, allow more efficient treatment and lessen the burden on already overloaded clinical laboratories. It will also alleviate the pressure on clinical microbiologists created by policies such as routine testing of inpatients for MRSA, and screening for $C$. diffecile. The recent occurrence of the swine flu pandemic may also create the opportunity that rapid point-of-care-diagnostics has been waiting for to show their real value and reliability during an infectious disease crisis. 


\section{Financial and competing interests disclosure}

The authors state that the projects, companies and devices included in the 'Five-year view' section are research partners of the authors, and that the autbors are involved in those finded projects as principal investigators. The authors' work on rapid diagnostics is funded by the MRCIEPSRC through the Technology Strategy Board, The NIHR i4i program, the European Community's Seventh Framework Program ([FP7/2007-2013] under grant agreement number 201914), PortFastFlu and the Countess Dowager Eleanor Peel Trust. The authors bave no other relevant affiliations or financial involvement with any organization or entity with a financial interest in or financial conflict with the subject matter or materials discussed in the manuscript apart from those disclosed.

No writing assistance was utilized in the production of this manuscript.

\section{Key issues}

- Infectious disease is a major health concern to the global population.

- Rapid diagnosis of infectious disease is a key strategy in lessening their burden.

- Molecular techniques based on pathogen genetics are key in developing rapid diagnostics.

- Key challenges are integrating complex procedures of sample preparation and assay into a single automated machine.

- Current and future research should see a rise in the number of reliable and robust point-of-care rapid diagnostic devices available to the healthcare profession.

\section{References}

Papers of special note have been highlighted as:

- of inrerest

-. of considerable interesr

1 Harris KA, Harcley JC. Development of broad-range $16 S$ rDNA PCR for use in the routine diagnostic clinical microbiology service. J. Med. Microbiol. 52, 685-691 (2003).

2 Whelen AC, Persing DH. The role of nucleic acid amplification and detection in the clinical microbiology laboratory. Ann. Rev. Microbiol. 50, 349-373 (1996).

3 Carricajo A, Boiste S, Thore J, Aubert G, Gille $Y$, Freydiere AM. Comparative evaluarion of five chromogenic media for detection, enumeration and identification of urinary tract pathogens. Eur. J. Clin. Microbiol. Infect. Dis. 18, 796-803 (1999).

4 Ledeboer NA, Das K, Eveland M et al. Evaluation of a novel chromogenic agar medium for isolation and differentiation of vancomycin-resistant Enterococcus faecium and Enterococcus faecalis isolates. J. Clin. Microbiol. 45, 1556-1560 (2007).

5 Samra Z, Heifetz M, Talmor J, Bain E, Bahar J. Evaluation of use of a new chromogenic agar in detection of urinary tract parthogens. J. Clin. Microbiol. 36, 990-994 (1998).

6 Perry JD, Ford M, Taylor J, Jones AL, Freeman R, Gould FK. ABC medium, a new chromogenic agar for selective isolation of Salmonella spp. J. Clin. Micrabial. 37, 766-768 (1999).

7 Cooke VM, Miles R], Price RG, Midgley G, Khamri W, Richardson AC. New chromogenic agar medium for the identificacion of Candida spp. Appl. Environ. Microbiol. 68, 3622-3627 (2002).

8 Hedin G, Fang H. Evaluation of two new chromogenic media, CHROMagar MRSA and $S$. aurets ID, for identifying
Staphylococcus aureus and screening methicillin-resistant $S$. aureus. J. Clinz. Microbiol. 43, 4242-4244 (2005).

9 Kipp F, Kahl BC, Becker Ket al. Evaluation of two chromogenic agar media for recovery and identification of Staphylococcus aureus small-colony variants. J. Clin. Microbiol. 43, 1956-1959 (2005).

10 Perry JD, Davies A, Butterworth LA, Hopley AL, Nicholson A, Gould FK. Development and evaluation of a chromogenic agar medium for methicillin-resistant Stapbylococcus autreus. J. Clin. Microbiol. 42, 4519-4523 (2004).

11 Proffitt MR, Schindler SA. Rapid detection of HSV with an enzyme-linked virus inducible system (ELVIS) employing a genetically modified cell line. Clin. Diag. Virol. 4, 175-182 (1995).

12 Cerqueira L, Azevedo NF, Almeida C, Jardim T, Keevil CW, Vieira MJ. DNA mimics for the rapid identification of microorganisms by fluorescence in situ hybridization (FISH). Int. J. Mol. Sci. 9, 1944-1960 (2008).

13 Vaneechoutte $M$, Van Eldere J. The possibilicies and limitations of nucleic acid amplification rechrology in diagnostic microbiology. J. Med. Microbiol. 46, 188-194 (1997).

14 Ieven $\mathrm{M}$, Goossens H. Relevance of nucleic acid amplification techniques for diagnosis of respiratory tract infections in the clinical laboratory. Clin. Microbiol. Reus. 10, 242-256 (1997).

15 Mullis KB, Faloona FA. Specific synthesis of DNA in vitro via a polymerase-catalyzed chain reaction. Met. Enzymol. 155, 335-350 (1987).

16 Higuchi R, Fockler C, Dollinger G, Watson $R$. Kineric PCR analysis: real-rime moniroring of DNA amplification reactions. Biotechnology 11, 1026-1030 (1993).
17 Call DR. Challenges and opportunities for parhogen detection using DNA. microarrays. Crit. Rev. Microbiol. 31, 91-99 (2005).

- Highlights in detail the potential for microarray technology in diagnostics.

18 Ubukata K, Nonoguchi R, Marsuhashi $M$, Konno $M$. Expression and inducibility in Stapbylococcus aureus of the mecA gene, which encodes a methicillin-resistant S. aureus-specific penicillin-binding protein. J. Bacteriol. 171, 2882-2885 (1989).

- Good example of how bacterial genomics informs diagnostic testing.

19 Fang H, Hedin G. Rapid screening and identification of methicillin-resistant Stapbylococcus aureus from clinical samples by selective-broth and real-time PCR assay. J. Clin. Microbiol. 41, 2894-2899 (2003).

20 Reischl U, Linde HJ, Metz M, Leppmeier B, Lehn N. Rapid identification of methicillin-resistant Staphylococcus aureus and simultaneous species confirmation using real-time fuorescence PCR. J. Clitr. Microbiol. 38, 2429-2433 (2000).

- Good example of the potential of real-time $P C R$ for diagnosing key infections.

21 Warren DK, Liao RS, Merz LR, Eveland $M$, Dunne WM Jr. Detection of methicillin-zesistane Staphylococcus aureus directly from nasal swab specimens by a real-time PCR assay. J. Clin. Microbiol. 42, 5578-5581 (2004).

- Excellent example of power of molecular detection methods on clinical samples.

22 Francois $P$, Pitcet $D$, Bento $M$ et al. Rapid detection of methicillin-resistant Staphylococcus aureus directiy from sterile or non-sterile clinical samples by a new molecular assay. J. Clin. Microbiol. 41, 254-260 (2003). 
23 Kox LF, Rhienthong D, Miranda AM et al. A more reliable PCR for detection of Mycobacterium tuberculosis in clinical samples. J. Clin. Microbiol. 32, 672-678 (1994).

24 Mercier B, Gaucher C, Feugeas O, Mazurier C. Direct PCR from whole blood, without DNA extraction. Nuch. Acids Res. 18, 5908 (1990).

25 Wiedbrauk DL, Werner JC, Drevon AM. Inhibition of $P C R$ by aqueous and vitreous Ruids. J. Clin. Microbiol. 33, 2643-2646 (1995).

26 Abu Al-Soud W, Radstrom P. Effects of amplification facilitators on diagnostic PCR in the presence of blood, faeces, and meat. J. Clin. Microbiol. 38, 4463-4470 (2000).

27 Fredricks DN, Relman DA. Improved amplification of microbial DNA from blood cultures by removal of the PCR inhibitor sodium polyanetholesulfonate. J. Clin. Micrabiol. 36, 2810-2816 (1998).

28 Morata P, Queipo-Ortuno MI, de Dios Colmenero J. Strategy for optimizing DNA amplification in a peripheral blood PCR assay used for diagnosis of human brucellosis. J. Clin. Microbiol. 36, 2443-2446 (1998).

29 Al-Soud WA, Radstrom P. Purification and characterization of PCR-inhibitory components in blood cells. J. Clin. Microbiol. 39, 485-493 (2001).

30 Widjojoatmodjo MN, Fluit AC, Torensma $\mathrm{R}$, Verdonk GP, Verhoef J. The magnetic immuno polymerase chain reaction assay for direcr detection of Salmonellae in faecal samples. J. Clin. Microbiol. 30, 3195-3199 (1992).

31 Amavisir P, Browning GE, Lightfoot $D$ et al. Rapid PCR detection of Salmonella in horse faecal samples. Vet. Microbiol. 79, 63-74 (2001).

32 Chui L,W, King R, Lu P, Manninen K, Sim $J$. Evaluation of four DNA excraction methods for the detection of Mycobacterium avium subsp. Paratuberculosis by polymerase chain reaction. Diag. Microbiol. Infect. Dis. 48 , 39-..45 (2004).

33 McOrist AL, Jackson M, Bird AR A comparison of five methods for extraction of bacterial DNA from human faecal samples. J. Microbiol. Met. 50, 131-139 (2002).

-. Excellent treatise on best methods to extract pathogen DNA from clinical material.
34 Fafi-Kremer S, Morand P, Barranger C et al. Evaluation of the Epstein-Barr virus R-gene quantification kit in whole blood with different extraction methods and PCR platforms. J. Mol. Diagn. 10, 78-84 (2008).

35 Pallen MJ, Wren BW. Bacterial parhogenomics. Nature 449, 835-842 (2007).

- Seminal article showing the challenges in identifying genes responsible for bacterial pathogenesis.

36 Lyras $D, O^{\prime}$ Connor JR, Howarth PM etal. Toxin $B$ is essential for virulence of Clostridium difficile. Nature 458, 1176-1179 (2009).

37 Goorhuis A, Bakker D, Corver J et al. Emergence of Clostriditum diffrile infection due to a new hypervirulent strain, polymerase chain reaction ribotype 078. Clin. Infect. Dis. 47, 1162-1170 (2008).

38 Wolff D, Bruning T, Gerritzen A. Rapid detecrion of the Clostridium difficile ribotype $027 \mathrm{tcdC}$ gene frame shift mutation at position 117 by real-time PCR and melt curve analysis. Eur. J. Clin. Microbiol. Infect. Dis. 8, 959-962 (2009).

- Example of how subtle pathogen-unique traits can be identified by molecular techniques.

39 Holland CA, Kiechle FL. Point-of-care molecular dingnostic systems - past, present and future. Curr. Opin. Microbiol. 8, 504-509 (2005).

-. Excellent overarching review on molecular diagnostics.

40 Espy MJ, Rys PN, Wold AD et al. Detection of herpes simplex virus DNA in genital and dermal specimens by LightCycler PCR afrer extraction using the IsoQuick, MagNA Pure, and BioRobot 9604 methods. J. Clin. Microbiol. 39, 2233-2236 (2001).

41 Fafi-Kremer S, Brengel-Pesce K, Bargues G et al. Assessment of automated DNA extraction coupled with real-time PCR for measuring Epstein-Barr virus load in whole blood, peripheral mononuclear cells and plasma. J. Clin. Virol. 30, 157-164 (2004).

42 Knepp JH, Geahr MA, Forman MS, Valsamakis A. Comparison of automared and manual nucleic acid extraction methods for derection of enterovirus RNA.J. Clin. Microbiol. 41, 3532-3536 (2003).

43 Loeffler J, Schmidt K, Hebart H, Schumacher U, Einsele H. Auromared extraction of genomic DNA from medically important yeast species and filamentous fungi by using the MagNA Pure LC system. J. Clin. Microbiol 40, 2240-2243 (2002)
44 Smith K. Diggle MA, Clarke SC. Comparison of commercial DNA extraction kits for extraction of bacterial genomic DNA from whole-blood samples. J. Clin. Microbiol. 41, 2440-2443 (2003).

45 Williams SM, Meadows CA, Lyon E. Automated DNA extraction for real-time PCR. Clin. Chem. 48, 1629-1630 (2002)

46 Costa C, Costa JM, Desterke C, Botrerel F Cordonnier C, Bretagne S. Real-time PCR coupled with aucomated DNA extraction and detecrion of galacromannan antigen in serum by enzyme-linked immunosorbent assay for diagnosis of invasive aspergillosis. J. Clin. Microbiol. 40, 2224-2227 (2002).

47 Gavino M, Wang E. A comparison of a new rapid real-time polymerase chain reacrion system to traditional culture in determining group B Streptococcus colonization. Am. J. Obstet. Gynecol. 197 381-384 (2007).

48 Kost CB, Rogers B, Oberste MS et al. Multicenter beta trial of the GeneXpert enterovirus assay. J. Clin. Microbial. 45 1081-1086 (2007).

49 Rossney AS, Herra CM, Brennan GI, Morgan PM, O'Connell B. Evaluation of the Xpert merhicillin-resistant Stapbylococcus aureus (MRSA) assay using the GeneXpert real-time PCR platform for rapid detection of MRSA from screening specimens. J. Clin. Microbiol. 46, 3285-3290 (2008)

- Shows ability of the Cepheid methicillinresistant Staphylococcus autreus device.

50 Slomka MJ, Pavlidis T, Banks J et al. Validated H5 Eurasian real-rime reverse transcriptase-polymerase chain reacrion and its application in $\mathrm{H} 5 \mathrm{Nl}$ outbreaks in 2005-2006. Av. Dis. 51, 373-377 (2007).

\section{Website}

101 Health Protection Agency www.hpa.org.uk/web/ HPAweb \& HFAwebStandard/ HPAweb_C/1244763936373

\section{Affiliations}

- Jennifer Ince School of Science and Technology, Nottingham Trent University, Clifton Lane, Notringham NG11 8NS, UK

- Alan McNaliy School of Science and Technology, Nortingham Trent University, Clifton Lane, Nottingham NGI1 8NS, UK Tel.: +441158483324 alan.menally@ncu.ac.uk 